\title{
LA POÉTICA DE LA FICCIÓN EN LA TEORÍA LITERARIA DE LOS SIGLOS XVI Y XVII
}

\author{
Juan Frau García \\ Universidad de Sevilla
}

\begin{abstract}
This paper offers a global view of the polemics in the matter of fiction, involving some concepts as truth and lie, in the poetics of the Spanish XVI and XVII centuries, and analyzes the continuous struggle between the artistic need to imaginate and the censorship of the moralists.
\end{abstract}

La reflexión sobre el hecho literario tiene un hito especialmente relevante en el debate que se establece en torno a la ficcionalidad, ya se se entienda como posible o necesaria, de la obra poética. Los términos de dicho debate han ido cambiando a lo largo de la historia, y, en la Teoría de la Literatura actual, las tensiones que se producen entre la realidad y la ficción constituyen uno de los principales argumentos a la hora de dilucidar el problema de la literariedad, sobre todo una vez que han quedado en punto muerto los intentos formalistas de encontrar cualidades lingüísticas necesarias y exclusivas en los textos literarios.

La manera de enfocar el asunto, lógicamente, era muy distinta en la poética clasicista, pero es posible encontrar en ella las raíces del debate actual, y aunque muchos de sus planteamientos estén condicionados por factores entonces determinantes y que hoy han perdido fuerza o razón de ser, como la autoridad casi absoluta y omnipresente de Aristóteles o la interrelación constante entre la ética y la estética, o más bien la supeditación de la segunda a la primera, lo cierto es que algunas de las ideas clásicas en torno a la ficción pueden calificarse de modernas -tal vez sea más adecuado decir que algunas ideas modernas al respecto pueden considerarse, en cierto modo, clásicas-, y tienen un pleno vigor hoy día. En las páginas siguientes se ofrece una revisión de las aportaciones más significativas al debate de la ficcionalidad que pueden encontrarse en los textos teóricos hispánicos de los siglos XVI y XVII, recogidos tanto en poéticas generales como en prólogos, comentarios o incluso en metaficciones insertas en el cuerpo de las obras literarias.

Puede comprobarse con facilidad que, si se prescinde de las poéticas, el conflicto que se da en la literatura entre la realidad y la ficción aparece reflejado sobre todo, y casi de una forma sistemática, en la sucesión de textos panegíricos y apologéticos que se componen en loor de la poesía y a modo de desagravio. Esto presupone, por lo tanto, que hay unos agravios previos -o que al menos se sienten como tales- que justifican tales defensas, y que se resumen en la idea tantas veces expresada de que los poetas son, en definitiva, mentirosos e inmorales, cuando no locos. Bernardo de Balbuena, que escribe justamente un Compendio apologético en alabanza de la poesía (1604), expone, con la intención de rebatirlas, una buena parte de las acusaciones formuladas por autores antiguos como Platón, 
Demócrito, Séneca o los santos Agustín y Jerónimo, cuya suma ofrece la impresión del poeta como ser ocioso, loco y deshonesto, nocivo para su sociedad y fabuloso ${ }^{1}$.

Lo que ahora importa es que casi todas las descalificaciones del poeta provienen de forma directa de ésta última, la de fabuloso, que Balbuena recoge del Fedro de Platón. Si se tiene al poeta por loco o por corruptor de sus lectores es porque inventa aquello que no se encuentra en la realidad perceptible sino que más bien contrasta con ella y puede llevar a confusión a quien lo lea. De ahí la inclusión del debate sobre la ficcionalidad literaria en los terrenos de la moral y en la polémica que se establece entre la verdad y la mentira. Dadas la mentalidad y la cultura de la época, y en espera de la posterior emancipación kantiana de la estética, no se puede hablar de un enfrentamiento entre arte y moral, sino más bien de una pugna entre los que observan dos realidades opuestas, la artística y la de la naturaleza, y aquellos que, por el contrario, tratan de conciliarlas justificando la compatibilidad de la estética con la ética.

Por un lado están quienes sostienen el tópico de que la poesía es engaño, normalmente moralistas y religiosos que juzgan al poeta desde una perspectiva ajena al arte. Esa distancia provoca la incomprensión, y asimila la ficción a la mentira. Juan Lerín y García es uno de esos moralistas que, ajenos al dominio de la estética y más interesados en otros mundos, juzgan con severidad y reprueban lo que acaso no comprenden. En El bien y el mal de las ciencias humanas (1626), Lerín dedica varios capítulos a la censura de la poesía profana. En primer lugar aporta un considerable número de testimonios tomados de la antigüedad clásica en los que se presenta al poeta, ya sea en general o en casos concretos, como "artífice de de mentiras y fabricador de novelas", "bueno para corromper las buenas costumbres", "polilla de las virtudes", y, en fin, como quien se cuenta entre las personas "inútiles y sin fruto"2. Algunos de esos testimonios, tomados con frecuencia de segunda o tercera mano, aparecen tergiversados de manera tendenciosa, como el que, mal recogido de Plutarco $^{3}$, se atribuye a Gorgias, pero lo que ahora se pretende subrayar no es, en cualquier caso, la exactitud o la fidelidad a las fuentes, sino la imagen que se quiere ofrecer de la poesía. Afirma Lerín que los poetas son unos mentirosos cuya profesión es "engañar al mundo y traelle divertido con trecientas mil quimeras y desatinos", pariendo "una infinidad de mentiras" ${ }^{\prime 4}$. En un capítulo posterior Lerín refuerza su crítica mediante la cita de seis lugares de las sagradas escrituras que, según él, condenan las fábulas de los poetas. Pero, más allá del resentimiento que contra la ficción poética evidencian los pasajes mencionados, son de algún interés dos comparaciones que introduce Lerín; la primera, tradicional, es la que muestra el contraste entre la historia y la poesía, puesto que ésta, a diferencia de la primera, "licencia tiene para decir lo que quisiere y para mentir muy a su

${ }^{1}$ B. de Balbuena, Compendio apologético en alabanza de la poesía (México 1604), en A. Porqueras Mayo, La teoría poética en el Renacimiento y Manierismo españoles (Barcelona, Puvill, 1986) 285.

2 J. de Lerín y García, El bien y el mal de las ciencias (París 1626), en La teoría poética en el Renacimiento y Manierismo españoles, cit., 170-171.

${ }^{3}$ Plauto, Obras morales y de costumbres (Madrid, Gredos, 2001) 54. Lerín interpreta que Gorgias dice de la tragedia "que es un embauco de sentidos, un hechizo de entendimientos, un trampantojo y embeleco de quien la oye". La cita completa y entendida en su sentido adecuado -el opuesto- se verá algo más adelante.

${ }^{4}$ J. de Lerín y García, loc. cit. 
salvo, sin pagar alcabala"5. La otra comparación es de nuevo fruto de la obsesión de Lerín por la impunidad de los poetas, pues señala que, frente a la responsabilidad que tiene cualquier persona cuando afirma algo en pública audiencia, el poeta se siente libre de decir lo que se le antoja sin ser reprendido por ello. Se trata de algo que también ha subrayado recientemente la Teoría Empírica de la Literatura, aunque, claro está, sin ningún tipo de valoración positiva o negativa, sino como simple constatación de un hecho: en virtud de la convención estética "un autor puede hacer declaraciones que no correspondan a la realidad, o proponer normas que no defiende como sujeto cívico, sin que por ello se vea sometido a condiciones de verificación ni a sanciones sociales" ${ }^{\prime 6}$. La indignación de Lerín se debe, pues, a que no es capaz de diferenciar la enunciación literaria de cualquier otro tipo de enunciación, y confunde así las figuras del narrador en tercera persona o del sujeto lírico con la persona real y concreta que ha compuesto la obra, por lo que toma los enunciados del texto poético como afirmaciones que se refieren a la realidad histórica y al mundo factual.

Para concluir con el repaso de las ideas de Lerín y García en torno a la creación poética, cabe destacar otra circunstancia que le produce rechazo y que es objeto de su censura: la arrogancia y la soberbia del poeta que, según Lerín, se demuestran y manifiestan en el hecho de crear sin respeto a límite alguno, incluso al margen de la verdad y de la realidad, contribuyen a establecer un inequívoco e inadmisible paralelismo entre la figura del poeta y la divinidad, símil que se traza y describe con clara indignación:

"No hay cosa inmensa en el cielo ni en la tierra, si no es Dios, y la licencia de los poetas es un como Dios, porque así como Dios todo lo que quiere hace, así ellos hacen todo lo que quieren, no teniendo su voluntad límite, ni coto en el mentir."

Cabe recordar que en otras ocasiones esa misma comparación se establece en términos positivos. Al igual que en ciertos movimientos literarios de la modernidad, como el Romanticismo o algunas vanguardias, aunque de manera menos arrogante, Luis Alfonso de Carballo establece la analogía entre Dios y el poeta, apelando a la etimología y al hecho de que "el Poeta de lo que nunca fue succedido hace un argumento y ficción, que parece auer subcedido haziendo algo de lo que era nada", en lo que imita a Dios -concluye Carballo-, aunque no perfectamente ${ }^{8}$. En principio, y pese a la indignación que mostraba Juan Lerín, dicha analogía es por completo compatible con la doctrina cristiana, que define al ser humano como una criatura hecha a imagen y semejanza de la propia divinidad, que tal vez mediante el obsequio de la capacidad artística y poética le concede, en el grado imperfecto del que hablaba Carballo, la condición de creador, aumentando así la susodicha semejanza. Parece oportuno comentar, siquiera brevemente, algunas implicaciones de lo que afirma Carballo, puesto que parece intuir y señalar de forma muy acertada la diferencia que media

\section{${ }^{5}$ Ibidem.}

${ }^{6}$ M. Iglesias Santos, "El sistema literario: Teoría Empírica y Teoría de los Polisistemas", en D. Villanueva (comp.), Avances en Teoría de la Literatura (Santiago de Compostela, Universidade de Santiago de Compostela, 1994) 323.

${ }^{7}$ J. de Lerín, loc. cit.

${ }^{8}$ L. A. de Carballo, Cisne de Apolo, Medina del Campo, 1602 (Madrid, CSIC, 1958) 229. Edición de A. Porqueras Mayo. 
entre lo ficticio y lo no existente, algo que no siempre se tiene en cuenta. Como ha precisado en nuestros días Martínez Bonati, es cierto que el ser ficticio sólo existe en nuestro pensamiento, aunque "éste no es un modo irreal, sino real, pero imaginario e ilusorio, de existencia" ${ }^{\prime}$, y Carballo no deja de reconocer, en este sentido, que el poeta hace algo a partir de la nada, "de lo que nunca fue sucedido", aunque lo creado sea apenas una ficción.

Otro moralista que condena sin paliativos la creación poética es Juan de Zabaleta, para quien "el oficio de la poesía es fingir lo que es o figurar lo que es, de tal manera que quede en otra especie. La mentira, de mentira afuera, es nada"10. Es decir, nada de provecho puede haber en lo que no tiene fundamento real alguno, y todo lo que aparece en la ficción carece de toda sustancia y toda validez fuera de dicha ficción. El planteamiento es prácticamente el opuesto al que hacía Carballo; se niega al poeta la capacidad creadora: no habría tal creación de una nueva realidad, sino más bien deformación o desfiguración -se finge lo que ya es- de la realidad preexistente, la que la experiencia del mundo real nos muestra. Además, mezclando la filosofía y la religión, afirma Zabaleta que la naturaleza es opuesta a lo malo, y la poesía es opuesta a la naturaleza, de lo que se deduce que la poesía es, en un sentido moral, mala.

Otro ejemplo -de entre los muchos posibles- del rechazo de la ficción, aunque parcial y con matices, lo tenemos en el Diálogo de la lengua de Juan de Valdés, donde el autor se lamenta amargamente de haber perdido diez años de su vida "en leer estas mentiras", refiriéndose a los libros de caballerías, que tacha de "mentirosíssimos"11. También se encuentra el rechazo de los libros de caballerías y de la ficción poética, como destaca Esteban Torre, en la obra de Francisco Sánchez el Brocense, quien habla de cierto caballero español "cuyo entretenimiento era escribir libros de caballerías, porque tenía cierta diferencia de imaginativa que convida al hombre a ficciones y mentiras"12. Con la opinión de Valdés y Sánchez coincide la de Miguel Sánchez de Lima, que en su dialogada Arte poética en romance castellano (1580) arremete igualmente contra los libros de caballerías, "todo mentiras y vanidades" y "que no sirven de otra cosa sino de corromper los ánimos de los mancebos y doncellas"13. Sánchez de Lima establece, sin embargo, una clara distinción entre dos tipos de poesía, una valiosa que "mata la necedad y destierra la ignorancia, aviva el ingenio, adelgaza y labra el entendimiento"14, que es la que en verdad merece el nombre de poesía, y otra constituida por los mencionados libros de caballerías y las fábulas inverosímiles de los autores paganos; así, se puede leer la siguiente petición:

${ }^{9}$ F. Martínez Bonati, La ficción narrativa (Su lógica y ontología) (Murcia, Universidad de Murcia, 1992) 102.

${ }^{10}$ J. de Zabaleta, Errores celebrados (Madrid 1653), en La teoría poética en el Manierismo y Barroco españoles (Barcelona, Puvill, 1989) 336.

${ }^{11}$ J. de Valdés, Diálogo de la lengua (Madrid, Cátedra, 1984), 248.

${ }^{12}$ E. Torre, Sobre lengua y literatura en el pensamiento científico español de la segunda mitad del siglo XVI (Universidad de Sevilla, 1984), 75.

${ }^{13}$ M. de Sánchez de Lima, Arte poética en romance castellano (1580), en La teoría poética en el Renacimiento y Manierismo españoles, cit., 131.

${ }^{14}$ Ibidem. 
"Holgaría en estremo que me dijésedes lo que sentís de las excelencias de la poesía, con tal condición que no me contéis fábulas de Ovidio, ni me digáis el cuento del caballo alado que entre los poetas es llamado el Pegaso, ni la fuente Cabalina, ni me tratéis de las ninfas, [...] porque no puedo sufrir esas ficciones [...] con que dejan suspensos a los mal entendidos lectores"15.

Así pues, las novelas de caballerías llegan a convertirse en una especie de paradigma de lo intrascendente, improductivo y aún dañino de la ficción. Conviene recordar, como lo hace Esteban Torre, cómo el doctor Huarte de San Juan, en su distinción y caracterización de los distintos ingenios, atribuye a la imaginativa el hecho de que algunos se desvivan por leer libros de caballerías y otras obras poéticas; señala Huarte, además, que quienes tienden hacia la imaginativa padecen, por el contrario, merma en el entendimiento ${ }^{16}$. No parece fácil, por lo tanto, que la poesía concuerde con la sabiduría; afirma Huarte que "por maravilla se halla hombre de grande imaginativa que tenga buen entendimiento ni memoria"17, lo que, podemos suponer, no necesariamente acerca la literatura a la mentira, pero sí dificulta su acceso a las verdades. Y de ahí que, como afirma Esteban Torre:

"La ficción de la poesía presenta en la obra de Huarte de San Juan un marcado carácter lúdico, en el que la dualidad docere et delectare se inclina sensiblemente hacia el segundo término"18.

En otras ocasiones llega a creerse incluso que la poesía perjudica a la verdad no tanto por las ficciones que contiene cuanto por su misma forma, por su continuo y necesario recurso al ornato. Se defiende que, por el contrario, la verdad ha de presentarse desnuda y valerse por sí sola, que es la sencillez lo que más le conviene y no la complejidad que conlleva la retórica. El lenguaje literario, según Francisco Sánchez el Escéptico, provoca con sus ambigüedades, figuras y circunloquios, contrarios de la claridad expositiva, un grave perjuicio a la unívoca comprensión de la verdad ${ }^{19}$, idea que también sostiene Huarte de San Juan ${ }^{20}$. Siempre ha existido, en mayor o menor medida, una cierta asociación entre la retórica y la mentira, y aún hoy, tal como se recoge en el diccionario de la Real Academia, una de las connotaciones del término "retórica" es la de un uso vacuo de la palabrería sofista.

En resumen, puede concluirse, a partir de los testimonios expuestos, que la poesía es con frecuencia condenada por su divergencia con la realidad, algo que viene dado por su condición ficticia y que, independientemente de cuál sea la ficción, hace que comparta con la mentira su apartamiento de la naturaleza y la verdad, algo inaceptable para la moral cristiana, al menos cuando se llevan al extremo ciertos criterios. Sin que sea opinión suya,

\footnotetext{
${ }^{15}$ Ibidem, 130.

16 Torre, E., Ideas lingüísticas y literarias del Doctor Huarte de San Juan (Sevilla, Universidad de Sevilla, 1977) 59-60.

${ }^{17}$ Huarte de San Juan, J., Examen de ingenios para las ciencias (Madrid, Editora Nacional, 1976) 128; cfr. 170 172, 203-204. Edición de E. Torre.

${ }^{18}$ Torre, E, Ideas lingüísticas y literarias del Doctor Huarte de San Juan, cit., 106.

${ }^{19}$ Vid. Torre, E., Sobre lengua y literatura en el pensamiento científico español...,cit., 121-122 y 140-141.

${ }^{20}$ Vid. Torre, E., Ideas lingüísticas y literarias del Doctor Huarte de San Juan, cit., 60-61.
} 
Francisco de Quevedo refleja en tono jocoso la idea de que el fingimiento de la poesía es análogo al de la mentira; en una de sus premáticas, dentro de una crítica más general a ciertos poetas, escribe: "Item, advertimos que la mitad de lo que dicen lo deben a la pila del agua bendita, por mentiroso, y que sólo dicen verdad en decir mal unos de otros"21. Existirían, pues, dos planteamientos fundamentales al respecto del problema de la ficción literaria. El primero es el que sostiene que los escritos literarios contienen una parte de verdad y otra de mentira, y que ésta, en términos generales, merece la censura. La otra postura es la de que, como sostenía Zabaleta y defiende hoy la filosofía analítica, todo cuanto se integra en la ficción, al margen de su procedencia, es necesariamente ficticio. En todo caso, sea cual sea la postura que se adopte, y según se irá viendo, entre quienes escriben sobre la poesía, y casi siempre en su defensa, se admite sin ambigüedades ni restricciones que la ficción es un ingrediente esencial. La clave para que ésta resulte aceptable residirá, según defienden los distintos poetas y teóricos de la época, en que se establezcan y respeten ciertos límites, en que se distinga la ficción de la falsedad o en que, al menos, se reconozca que las ficciones, de manera paradójica, no necesariamente carecen de una sustancia verdadera.

Ya antes, en el siglo XV, se había recurrido a algunas de estas vías como solución del dilema moral, y, en ciertas ocasiones, el hecho de que se trate de ficciones absolutas sirve, precisamente, como argumento de disculpa para el poeta; con frecuencia el poeta queda a salvo de las acusaciones de mentiroso gracias a que lo que cuenta es, de forma patente, inverosímil, con lo que no se puede creer que pretenda engañar a nadie. La mentira sólo puede cumplir su cometido con éxito si es capaz de ocupar el lugar de la verdad y de ser confundida con ella, para lo que es necesario cierto grado de verosimilitud; el poeta que lleva a cabo fabulaciones increíbles sería, por lo tanto, un mentiroso muy poco hábil. Ésta ha sido tal vez la disculpa más convincente ante una de las principales y más antiguas acusaciones formuladas contra el poeta y la poesía desde los albores de la Edad Media, que tenía como base el carácter pagano de los textos literarios. Los primeros cristianos creen en una inspiración demoníaca de la poesía, y Titiano, por ejemplo, acusa a los poetas de haber inventado la poesía para cantar las batallas, los amores de los dioses y todo lo que corrompe el espíritu. Contra acusaciones de esa índole responde el poeta Juan del Encina en el prohemio al Cancionero (1496), donde justifica que los escritores invoquen a las musas y a dioses antiguos tales como Apolo, Mercurio o Baco, puesto "que siendo fición la obra, es mucha razón que no menos sea fingida y no verdadera la invocación della"22.

Aunque tanto la formulación como la propia sustancia de lo afirmado sean distintas, no deja de haber un claro parentesco entre lo que sostiene Juan del Encina y las ideas de la Pragmática moderna, según las cuales en el texto literario todo enunciado tiene un estatuto especial y debe considerarse un cuasi-acto de habla o un uso no serio del lenguaje en el que

${ }^{21}$ F. de Quevedo, Premáticas del Desengaño contra los poetas güeros, en Prosa festiva completa (Madrid, Cátedra, 1993), 187.

22 J. del Encina, Cancionero (Salamanca, 1496), en A. Porqueras Mayo, La teoría poética en el Renacimiento y Manierismo españoles, cit., 79. 
el autor finge hablar pero no habla en realidad ${ }^{23}$, o bien, tal vez con más precisión, un acto pleno de habla pero en el que el autor finge ser alguien distinto que está haciendo afirmaciones seriamente ${ }^{24}$. Queda claro, en definitiva, que el autor no responde personalmente de las afirmaciones que aparecen en su obra, y no debe ser censurado por ellas.

Otro argumento recurrente en las apologías medievales y de los Siglos de Oro es el de que, como se ha dicho, a veces la ficción contiene verdades y cumple justamente una función moral y didáctica. Una muestra de ello es la célebre definición que hace de la poesía el Marqués de Santillana: "¿E qué cosa es la poesía, que en el nuestro vulgar gaya sciencia llamamos, sino un fingimiento de cosas útiles, cubiertas o veladas con muy fermosa cobertura? ${ }^{25 "}$. Precisamente, la justificación más frecuente de la literatura a lo largo de la historia de la Poética ha sido la que le ha atribuido la capacidad de alcanzar y divulgar un adecuado conocimiento del universo, llegando en ciertas épocas incluso a considerarse que sólo la poesía puede penetrar en la verdadera y última esencia de las cosas. Argumentos moralizantes, además, sirven con frecuencia para defender las ficciones de la poesía, como los que emplea Sancho Muñón en el prólogo de Lisandro y Roselia, donde, después de una exposición demorada del conflicto, llega a la misma conclusión que Santillana. Dice Muñón que hay quienes reniegan de las ficciones por falsas y sólo aprecian la doctrina de la filosofía moral, pero que, por el contrario, resulta que la ficción poética es gran auxiliar de la persuasión, y que, por añadidura,

"los poetas no son sino de filosofía y otras sciencias, mas porque vieron que la doctrina de la verdad no es muy suave de oír para muchos, quisiéronla envolver en fábulas, porque de mejor gana los lectores se afictionasen a percibir aquella doctrina amarga con el dulzor de la ficción fabulosa". ${ }^{26}$

Muñón, como es habitual, recurre a las autoridades, y recuerda que Sócrates "era grande artífice de ficciones" cuando quería persuadir, y que Aristóteles defiende el valor de los ejemplos para la persuasión, ya sean fingidos o verdaderos ${ }^{27}$. Aunque no hay demasiada originalidad en estos planteamientos, tomados de la poética y la retórica clásicas, menos frecuente y en apariencia más moderno -sólo en apariencia, porque de hecho lo toma de Plutarco y de Gorgias- es el que añade poco después y que consiste en defender que la ficción es un "buen engaño" que no sirve para los hombres "que tienen bajo entendimiento y grosero, porque estos tales no se dejan así engañar", y que la literatura hace más sabios a

${ }^{23}$ Cfr. J. L. Austin, Cómo hacer cosas con palabras (Barcelona, Paidós, 1990), 50, 63, 148; W. Iser, El acto de leer (Madrid, Taurus, 1987), 93-100; J. M. Pozuelo Yvancos, Poética de la ficción (Madrid, Síntesis, 1993), 7382; M. del C. Bobes Naves, La novela (Madrid, Síntesis, 1993), 252-258; A. Garrido Domínguez, Teorías de la ficción literaria (Madrid, Arco/Libros, 1997), 33.

${ }^{24}$ F. Martínez Bonati, La ficción narrativa (Su lógica y ontología), cit., 162.

${ }^{25}$ I. López de Mendoza, Prohemio e carta (1449), en A. Porqueras Mayo, La teoría poética en el Renacimiento y Manierismo españoles, cit., 76.

${ }^{26}$ S. Muñón, Tragicomedia de Lisandro y Roselia, en La teoría poética en el Renacimiento y Manierismo españoles, cit., 89. Cfr. L. A. de Carballo, Cisne de Apolo, cit., 115.

${ }^{27}$ Ibidem, 90. 
quienes se dejan engañar que a los que rehúyen el engaño. De nuevo, si dejamos a un lado los criterios de utilidad, encontramos una postura relativamente cercana a las de la Pragmática y la Teoría de la Recepción, según las cuales la comunicación literaria sólo puede tener éxito si el lector quiere colaborar en el proceso -en el cual, por otra parte, tiene la iniciativa- y si, además, posee el adecuado dominio y conocimiento de las convenciones pertinentes. Como se ha dicho en otro lugar, "el lector experimentado y competente sabe distinguir la ficción de la realidad, y es para él para quien escribe el autor de la obra, que no encontraría recompensa o satisfacción alguna por el hecho de engañar a un lector poco preparado"; el autor y el lector "establecen un juego implícito y en cierto modo también pactado: el lector se abandona a la trampa y fomenta su propia ingenuidad" ${ }^{28}$ para perderse en la ficción.

Aunque la aceptación voluntaria y convencional de lo ficticio por parte del lector, mediante la suscripción de un "pacto de lectura"29, se justifique hoy día fundamentalmente por la aspiración al disfrute de un goce estético, la teoría literaria renacentista y barroca recurre a la justificación moral y didáctica, como se ha visto en el caso de Muñón. Después que él, Alejo de Venegas, Sánchez de Lima, Bernardo de Balbuena, Hernando de Soto o Suárez de Figueroa, entre otros, recurren a tales argumentos. Alejo de Venegas sostiene que "la poesía no es una ficción vana, como lo piensa el vulgo", sino que "es una ficción racional que sirve de cifra de alguna verdad natural, historial o moral"30; Bernardo de Balbuena afirma que las ficciones de Homero y los poetas griegos son estímulos a la virtud $^{31}$; Hernando de Soto defiende que los antiguos escribieron fábulas "por enseñar doctrina a los de tierna edad, y hacerlos aficionados a ella, dorándosela, como píldora con las ficciones de agradables cuentos", y añade que, aun siendo de composición fingida, "con todo eso ocultan mucha sustancia"32; Cristóbal Suárez de Figueroa, por su parte, dice que "está claro el provecho de las fábulas" ${ }^{133}$, lo que ejemplifica a continuación con algún caso concreto.

No obstante, la utilidad y el grado o la cualidad de la ficción pueden ir relacionados entre sí. Tanto Suárez de Figueroa como Alejo de Venegas y Alonso López Pinciano distinguen varios tipos de obras según el equilibrio que se establece entre la fición, la verdad y la realidad histórica. Pinciano y Venegas reconocen tres tipos: fábulas

\footnotetext{
${ }^{28}$ J. Frau, Realidades y ficciones del texto literario (Sevilla, Padilla, 2002) 169.

${ }^{29}$ Cfr. W. C. Booth, La retórica de la ficción (Barcelona, Bosch, 1978) 49; P. Macherey, Para una teoría de la producción literaria (Caracas, Universidad Central de Venezuela, 1974) 71 y ss.; J. M. Pozuelo Yvancos, op. cit., 118, 144-150, 236, 249; R. Bourneuf y R. Ouellet, L'univers du roman (París, Puf, 1981) 76-81; D. Villanueva, Teorías del realismo literario (Madrid, Espasa-Calpe, 1992) 79, 81, 114, 146.
}

${ }^{30}$ A. de Venegas, El momo de León Baptista Alberti (Alcalá, 1553), en La teoría poética en el Renacimiento y Manierismo españoles, cit., 91-92.

${ }^{31}$ B. de Balbuena, Compendio apologético en alabanza de la poesía, "cit., 273.

${ }^{32}$ H. de Soto, Emblemas moralizadas (Madrid, 1599), en La teoría poética en el Renacimiento y Manierismo españoles, cit., 211.

${ }^{33}$ C. Suárez de Figueroa, Plaza universal de todas las ciencias y artes (Madrid, 1615), en La teoría poética en el Renacimiento y Manierismo españoles, cit., 369. 
mitológicas, fábulas apologéticas y fábulas milesias. La primera clase, según Venegas, consiste en "un habla que con palabras de admiración significa algún secreto natural o cuento de historia" ${ }^{34}$ y, en palabras de Alonso López Pinciano, "casi siempre se fundan en alguna historia" y "sobre una verdad edifican mil ficciones" ${ }^{135}$; el segundo tipo es ejemplar, y "debajo de una hablilla muestran un consejo muy fino y verdadero"36; la fábula milesia, sin embargo, "es un desvarío vano sin meollo de virtud ni sciencia urdido para embobecer a los simples"17, entre los que Venegas cita como ejemplos destacados la Cabbala, el Talmud o el Alcorán, junto al Asno dorado de Apuleyo y, de nuevo, los libros de caballerías. Suárez de Figueroa, a su vez, y citando a Paulo Suardo, no distingue tres, sino cuatro especies de fábula, aunque la división no resulta tan clara: el apólogo equivaldría a las fábulas de Esopo, la figura mezcla lo verdadero y lo fabuloso, la parábola tiene más de historia que de fábula, y "la cuarta no retiene en sí alguna verdad, siendo pura invención, llamada patraña o conseja"138. El Pinciano encuentra una clara diferencia entre la mentira poética y la simple mentira; más allá de la distinta cualidad del artificio, sostiene el autor que la una deleita y enseña en tanto que la otra enoja y desinforma ${ }^{39}$.

Así pues, los autores de los siglos XVI y XVII se basan, a la hora de distinguir las distintas formas de fabulación, en las proporciones en que éstas combinan lo histórico, lo verdadero, lo útil, lo ficticio verosímil y lo ficticio inverosímil ${ }^{40}$, en todo lo cual subyace una clara valoración apenas disimulada en favor de la verdad moral. Todas las especies de fábula parecen aceptarse sin reservas salvo los cuentos milesios, que no sólo carecen de cualquier verdad en su peripecia, sino que, por inverosímiles, no tienen utilidad alguna ni aplicación en la vida práctica; la ficción se acepta en tanto que refleja en alguna medida aspectos del mundo real, cuyo mejor conocimiento hace posible. Sin embargo, no hay que deducir de lo precedente que la incorporación de la verdad histórica a la fábula sea unánimemente elogiada. De hecho, este problema se convierte en una de las principales discusiones de los tratadistas que se ocupan de la ficción poética, y que, en su mayor parte, se basan en las ideas de Aristóteles al respecto. Es de raíz aristotélica, por lo pronto, la distinción que se suele hacer entre historia y poesía; tanto el Pinciano como Cascales retoman la consabida idea de que la poesía es más universal que la historia ${ }^{41}$, pero no hay acuerdo unánime sobre si la ficción ha de ser total o puede ser parcial.

${ }^{34}$ A. de Venegas, op. cit., 93.

${ }^{35}$ A. López Pinciano, Philosophía antigua poética (Madrid, Biblioteca Castro, 1998) 175.

${ }^{36}$ A. López Pinciano, ibidem.

${ }^{37}$ A. de Venegas, loc. cit.

${ }^{38}$ C. Suárez de Figueroa, Plaza universal de todas las ciencias y artes, cit., 369.

${ }^{39}$ A. López Pinciano, op. cit., pág. 496.

${ }^{40}$ Cabe comparar estas distinciones con las que hace Tomás Albaladejo entre los modelos de mundos posibles, que serían de tres tipos: el de lo verdadero, el de lo ficcional verosímil y el de lo ficcional no verosímil; vid. T. Albaladejo, Teoría de los mundos posibles y macroestructura narrativa (Universidad de Alicante, 1998) 58-59.

${ }^{41}$ Vid. A. L. Pinciano, op. cit., 148-149; F. Cascales, Tablas poéticas (Murcia, 1617; Madrid, Espasa Calpe, 1975) 45-46. Cfr. A. García Berrio, Introducción a la poética clasicista: Cascales (Barcelona, Planeta, 1975) 116-125. 
Hay quien establece una frontera precisa y más o menos infranqueable, como José Pellicer, quien dice de ciertos autores que "no son poetas sino historiadores porque no imitan en sus escritos a la cosa, sino escriben la cosa como fue" ${ }^{142}$, aunque precisa que "el contexto se ha de fundar en la historia verdadera, los episodios han de ser fabulosos, la historia admirable, la fábula verisímil" ${ }^{43}$. Manuel de Faria e Sousa, por su parte, establece siete preceptos que debe cumplir el poema heroico para ser perfecto, entre los que se halla el de que en la obra poética no debe participar la historia, sino que ha de ser "hermosa invención"44; más adelante recuerda la acusación hecha contra Camoens, que él no comparte, ya que "se dice que siguió mucho la verdad de los sucesos y que el poema pide más fábula"45, repitiendo más tarde el principio de que la verdad histórica no debe ser protagonista de la obra poética, al menos en la épica, donde se ha de imponer la invención y la elaboración artística de los hechos. Ahí reside gran parte del valor y el mérito de la creación literaria; López Pinciano afirma precisamente que "la prestancia de la poética sobre la historia en eso consiste: que el poeta escribe lo que inventa y el historiador se lo halla guisado"46. Faria e Sousa insiste en que la ficcionalidad es requisito indispensable para la poesía, y dice en otro lugar que "no son poetas los que escriben sin alegóricas ficciones, sino lucidos versificadores" ${ }^{47}$.

Otros autores, por el contrario, defienden de manera explícita la necesidad de combinar ficción e historia. Luis Carrillo y Sotomayor, en la línea aristotélica, explica cómo la historia sirve para contar las cosas hechas, pero la poesía declara lo acontecido y lo no acontecido, "imitando como si fueran, como si pudieran ser o como debieran forzosamente o con semejanza a verdad"48. También Pedro Soto de Rojas encuentra necesario el equilibrio: "la forma sustancial de la poesía es la imitación variada con narración de cosas, en parte verdaderas y en parte fingidas"49. Para Juan López de Cuéllar, serían "verdad y ficción centros fijos desde donde el arte pueda tirar las líneas" ${ }^{\prime 50}$, bien hacia un sentido, bien hacia el otro. Y Juan Caramuel advierte que "la poesía es más amplia que el ser", ya que "los poetas tratan sobre cualquier cosa existente, y además de lo que ni existe ni puede

${ }^{42}$ J. Pellicer de Tovar, Epílogo de los preceptos del poema heroico (Madrid 1625), en La teoría poética en el Manierismo y Barroco españoles, cit., 167.

${ }^{43}$ Ibidem, 168.

${ }^{44}$ M. de Faria e Sousa, Los Lusiadas de Luis de Camoens (Madrid, 1639), en La teoría poética en el Manierismo y Barroco españoles, cit., 249.

${ }^{45}$ M. de Faria e Sousa, op. cit., 264.

${ }^{46}$ A. López Pinciano, op. cit., 174.

${ }^{47}$ M. de Faria e Sousa, Juicio de rimas varias de Luis de Camoens (Lisboa, 1685), en La teoría poética en el Manierismo y Barroco españoles, cit., 388.

${ }^{48}$ L. Carrillo y Sotomayor, Libro de la erudición poética, (1611; Sevilla, Alfar, 1987) 51.

${ }^{49}$ P. Soto de Rojas, Discurso sobre la poética (1612), en La teoría poética en el Renacimiento y Manierismo españoles, cit., 360 .

${ }^{50}$ J. López de Cuéllar y Vega, Declamación histórica y jurídica en defensa de la poesía (Madrid 1670), en La teoría poética en el Manierismo y Barroco españoles, cit., 358. 
existir"51; a continuación, Caramuel se preocupa de distinguir la ficción de la mentira, aunque ni él mismo acaba de convencerse, ya que precisa que "en la ficción, si se prescinde de la mentira, nada se encuentra que no sea digno de alabanza"s2, y algo más adelante recurre al argumento tópico de la utilidad moral de la ficción: "son hermosas y útiles estas hipótesis, pues gracias a ellas se nos amonesta para que abandonemos los vicios" ${ }^{153}$. Es significativo que utilice el término hipótesis para referirse a la ficción, algo que han hecho en tiempos recientes autores como Wolfgang Iser, que ha defendido que la ficción es una forma de mediación entre el sujeto y la realidad que aparece, por lo tanto, en las hipótesis de la ciencia y en las conjeturas cotidianas ${ }^{54}$.

Uno de los autores que en el siglo XVII realizan un análisis más agudo, penetrante y moderno de la ficción poética es Bernardo de Balbuena. En el prólogo que escribe para su poema épico El Bernardo, Balbuena defiende el equilibro que debe haber en la fábula entre una base real y la ficción, y señala cómo, por ser incierta la historicidad de la materia de Roncesvalles y los Doce Pares, puede parecer que "entra esta mi obra manca, pues toda su máquina se funda sobre cimiento dudoso"s5, pero ante esa objeción apela a la doctrina de Aristóteles y responde que "la poesía ha de ser imitación de verdad, pero no la misma verdad" y que el poema heroico ha de ser imitación, "donde en la palabra imitación se excluye la historia verdadera"56. Si la palabra imitación implica cierta semejanza entre lo imitado y su copia, no es menos cierto que también implica cierta diferencia entre ambos objetos. Este planteamiento coincide con el de la interpretación de la mímesis que en tiempos recientes han llevado a cabo Lubomír Dolezel, Käte Hamburguer o Gerard $\mathrm{Genette}^{57}$, quienes entienden que mímesis es equivalente a poiesis o invención creadora, esto es, que la obra literaria no puede ni debe limitarse a imitar prototipos reales tras su observación, sino que lo importante es que el lector encuentre expuestos unos hechos coherentes y verosímiles, que podrían ser incluso imposibles sin menoscabo del valor de la obra, como ya estableció Aristóteles en su Poética, donde decía preferir para la epopeya los asuntos imposibles, pero verosímiles, a los asuntos posibles pero improbables ${ }^{58}$.

\footnotetext{
${ }^{51}$ J. Caramuel de Lebkowitz, Primus Calamus (1665), en La teoría poética en el Manierismo y Barroco españoles, cit., 354.

${ }^{52}$ Ibidem.

${ }^{53}$ Ibidem, 355.

${ }^{54}$ W. Iser, El acto de leer (Madrid, Taurus, 1987), 92; W. Iser:, "La ficcionalización: dimensión antropológica de las ficciones literarias", en A. Garrido Domínguez (comp.), Teorías de la ficción literaria (Madrid, Arco/Libros, 1997) 46. Cfr. J. M. Pozuelo Yvancos, Poética de la ficción, cit., 11-12; cfr. J. Frau, Realidad y ficciones del texto literario, cit., 238.
}

${ }^{55}$ B. de Balbuena, El Bernardo (Madrid 1624), en La teoría poética en el Manierismo y Barroco españoles, cit., 122

${ }^{56}$ Ibidem, 123.

${ }^{57}$ Cfr. L. Dolezel, Heterocósmica. Ficción y mundos posibles (Madrid, Arco/libros, 1999) 10-25; K. Hamburguer, La lógica de la literatura (Madrid, Visor, 1995), 16-18; G. Genette, Ficción y dicción (Barcelona, Lumen, 1993) 16.

${ }^{58}$ Aristóteles, Poética (Sevilla, Padilla, 1997) 67. 
Reconoce también Balbuena la diferencia técnica que existe entre los textos históricos y los poéticos, y distingue dos modos de contar, uno natural y otro artificial, respectivamente. La distinción, que no es original y que retoma la oposición clásica entre el comienzo de la narración $a b$ ovo o in medias res, contempla algo tan evidente como importante: el hecho esencial de que el texto literario está sometido a una elaboración artística -artificial-, cuestión ésta que también se puede poner en relación con el asunto de la ficción o la mentira, y es que para Luis Alfonso de Carballo ahí radica la diferencia entre ambas; cuando Zoylo, interlocutor en Cisne de Apolo, afirma que el oficio del poeta es mentir, se le responde lo siguiente:

"Nunca a los Poetas es lícito mentir, ni su officio es mentir absolutamente. [...] Si el fingir fuesse sin su limitación y concierto, no puedo negar que sería mentir, mas quando es conforme a cierta orden y limitación, no es mentir. ${ }^{159}$

Es decir, la diferencia entre la simple mentira y la ficción literaria es que la segunda está sujeta al arte y elaborada según sus convenciones. En cuanto a esto último, y retomando el discurso de Balbuena, cabe destacar que el éxito de la obra literaria depende precisamente de la habilidad del poeta para engañar al lector: "Sirve también este modo, de contar las cosas con artificio, de engañar disimuladamente el receloso gusto del lector, que siempre con la prolijidad se cansa"60. Aprecia Balbuena, pues, que hay hechos pertinentes o funcionales en la obra literaria y otros que, por prescindibles o contraproducentes desde un punto de vista artístico no aparecen en ella; así, justifica, por ejemplo, la no inclusión en su poema épico de la educación o la crianza de su personaje, Bernardo del Carpio. En cierto modo, con ese rechazo de la prolijidad Balbuena intuye y constata lo que hoy día argumentan los filósofos analíticos, que los mundos de ficción son necesariamente menos densos que los mundos reales -que se definen y caracterizan precisamente por su totalidad o su carácter completo- ${ }^{61}$; para el lector de una obra literaria, que no suele ser receloso pese a las reticencias de Balbuena sino más bien entregado, sólo existe aquello que se le presenta en el relato, y no se plantea la existencia de lo que en él no aparece.

Un aspecto en el que Balbuena se adelanta a su época de forma notable es la reflexión explícita sobre la relación que existe entre la técnica narrativa y la verosimilitud, y cómo todo ello se utiliza para engañar mejor a los lectores. Afirma que "para mejor tejer las narraciones de un poema tan largo" procuró:

"que la persona del autor hablase en él lo menos que fuese posible, con que también se pudo añadir a la fábula más deleite; siéndole por esta vía permitido el extenderse a cosas más admirables, sin perder la verisimilitud; porque si la persona del poeta contara los monstruos de Creta o el origen de la ciudad de Granada, careciera lo uno y lo otro de apariencia de

${ }^{59}$ L. A. de Carballo, Cisne de Apolo, cit., tomo I, 79-80.

${ }^{60}$ B. de Balbuena, op. cit., 124.

${ }^{61}$ Cfr. L. Dolezel, "Mundos de ficción: densidad, vacíos e inferencias", en J. M. Pozuelo y V. Gómez (eds.), Mundos de ficción. Actas del VI Congreso Internacional de la Asociación de Semiótica (Universidad de Murcia, 1996) 14. 
verdad; mas referidos estos casos por tercera persona, queda con todo lo admirable, y el autor no fuera de lo verisímil". 62

La reflexión, por completo acertada, concuerda con la tendencia de los novelistas modernos que desde finales del siglo XIX tratan de renovar las técnicas narrativas. Como señala Wayne C. Booth, autores de esa época como James o Conrad y de la primera mitad del XX, cuales Joyce, Proust, Faulkner, Hemingway, Sartre o Robbe-Grillet, pretenden intensificar la ilusión de realismo y autenticidad precisamente mediante la supresión de las intervenciones del narrador, que va pareja al rechazo de la omnisciencia, la búsqueda de la objetividad y el desapasionamiento, entre otros recursos que configuran una retórica del disimulo ${ }^{63}$.

Hemos visto cómo Balbuena, especialmente en el último párrafo citado, insiste en la importancia de mantenerse dentro de lo verosímil. El de la verosimilitud es uno de los conceptos esenciales para articular la oposición entre realidad y ficción, como resulta manifiesto desde la Poética de Aristóteles, y ha merecido estudios y reflexiones que exceden por su hondura, su importancia y su cantidad a los propósitos y las posibilidades de este artículo; en todo caso, no es posible realizar un análisis de la ficcionalidad sin aludir a la verosimilitud, y, a manera de sucinto recordatorio, cabe subrayar el hecho de que los teóricos y los escritores de la época de la que ahora nos ocupamos tienen presente de manera constante el papel clave que ésta desempeña en la literatura. Al margen de las poéticas fundamentales, sobre todo la del aristotélico Cascales, se encuentran constantes referencias al respecto, y la condición de verosímil se convierte en punto esencial de la crítica literaria. Valdés critica como uno de los mayores vicios de las obras -y es, por ejemplo, el único reproche que le hace al Amadís- la falta de verosimilitud ${ }^{64}$; Suárez de Figueroa destaca que la poesía de Homero parece "una imagen verdadera de la vida humana"65; Fray Francisco González elogia especialmente el parecido con la realidad de Los amantes de Teruel, de Juan Yagüe de Salas, que sólo se apartaría de lo verosímil "por arrimarse como filósofo moral a la alegoría", y añade que los errores y lapsos que hay son justificables, porque no es historiador sino poeta que tiene licencia para ello ${ }^{66}$. En la nota liminar dedicada a los lectores de la Segunda parte de la vida de Lazarillo de Tormes, Juan de Luna reprocha al anónimo autor de una continuación anterior del Lazarillo la inverosimilitud de la historia -en la que Lázaro se metamorfosea en atún-, llena de "disparates $\tan$ necios como mentirosos, y tan mal fundados como necios"67, cuya corrección le empuja a hacer pública la supuesta verdad, respaldada por el "archivo de la

${ }^{62}$ Ibidem.

${ }^{63}$ W. C. Booth, La retórica de la ficción (Barcelona, Bosch, 1978).

${ }^{64} \mathrm{~J}$. de Valdés, op. cit., 251.

${ }^{65}$ C. Suárez de Figueroa, Varias noticias importantes a la humana comunicación (1621), en La teoría poética en el Manierismo y Barroco españoles, cit., 68.

${ }^{66}$ F. González, Carta encomial y apologética (Valencia, 1616), en La teoría poética en el Renacimiento y Manierismo españoles, cit., 380-382.

${ }^{67}$ J. de Luna, Segunda parte de la vida de Lazarillo de Tormes (París, 1620; Madrid, Cátedra, 1988), 266. Edición de Pedro Piñero. 
jacarandina de Toledo", lúdica perversión del tópico del manuscrito hallado, confundiendo a propósito la verdad con la verosimilitud.

Se trata, en su conjunto, de consideraciones artísticas, no morales; no se exige la verdad de los hechos, sino un carácter coherente y creíble que permita al lector encontrarse un mundo ficticio pero cabal, en el que los acontecimientos se sucedan de acuerdo con leyes semejantes a las que gobiernan el mundo real.

López Pinciano, por su parte, introđuce un elemento importante: al igual que Balbuena, observa que la verosimilitud no es sóla asunto de la elección del tema o de la invención de unos hechos determinados, sino que depende en gran medida de los elementos técnicos y formales, y subraya que el metro es enemigo de la imitación - ¿El que habla en metro, a quién imita?, ¿qué rústicos, qué plebeyos, qué ciudadanos hablan en metro, como en las bucólicas y cómicas?" ${ }^{68}$-, y defiende, como Aristóteles, que no hay que confundir poesía y verso, pues los hay que escriben en verso sin imitar -sin fingir-, y que sólo serían metrificadores. Lo mismo dice, como se ha mencionado, Faria e Sousa, y lo mismo dirá más tarde el menor de los Argensola, que no son poetas los que no fingen, sino versificadores, y en ello insiste Diego de Colmenares, según el cual la esencia de la poesía es la ficción, y el verso o la prosa son meros accidentes ${ }^{69}$.

Así pues, tanto lo formal como lo relativo al asunto son elementos determinantes para ocultar o, por el contrario, exhibir el carácter ficcional de un texto. A veces, la relación entre realidad y ficción llega a constituirse en un rasgo genérico, como sucede en la novela pastoril y en la égloga, que tienden a ofrecer una interpretación en clave y a encubrir la identidad de personas reales mediante la construcción de personajes ficticios. La convención es patente, por ejemplo, en Garcilaso o en Montemayor, quien escribe en la dedicatoria de La Diana que en ella se hallarán "muy diversas historias de casos que verdaderamente han sucedido, aunque van disfrazados debajo de nombres y estilo pastoril" ${ }^{170}$.

En resumen, según lo visto hasta el momento puede afirmarse que hay dos líneas, en principio divergentes pero que en ocasiones convergen, de manera paradójica, entre la verdad y la ficción en la literatura. Una es la línea que siguen los moralistas, quienes rechazan todo apartamiento de la verdad y no encuentran justificación en ningún motivo artístico; hablan más de mentira que de ficción. La otra es la postura de quienes se preocupan en primer término de la poesía, aunque rara vez prescinden por completo de valoraciones morales, y con frecuencia terminan por justificar la ficción apelando a la alegoría y a la función didáctica que realiza el texto literario, para lo que a menudo se toma como referencia la parábola evangélica. Entre quienes reivindican la ficción literaria por motivos artísticos y con razones estéticas, se plantean otros debates subsiguientes, como se

\footnotetext{
${ }^{68}$ A. López Pinciano, op. cit., 116. Vid. también págs. 150-155. Cfr. E. Torre, Sobre lengua y literatura en el pensamiento científico español de la segunda mitad del siglo XVI, cit., 130-132.

${ }^{69}$ D. de Colmenares, Respuesta a la carta antecedente por sus mismos puntos (1624), en La teoría poética en el Manierismo y Barroco españoles, cit., 112.

${ }^{70}$ J. de Montemayor, La Diana (Barcelona, Crítica, 1996) 8. Edición de J. Montero; vid. nota al pie.
} 
ha señalado, sobre la índole de la verosimilitud y las relaciones entre la literatura y la historia, tomando en consideración aspectos temáticos, formales e incluso relativos a la recepción del texto por parte del lector. En alguna ocasión se une lo relativo a la forma con el contenido, como hace Carballo:

"Esto está aueriguado, no ser mentira las fictiones de los Poetas, como en ellas se guarde la forma poética, sino ciertas señales con que se significan las verdades" ${ }^{\prime 71}$.

Aunque hay quien defiende la absoluta ficcionalidad de la obra literaria, y considera que la poesía constituye una espeeie de dominio prácticamente autónomo, regido por sus propias leyes y situado al margen de la realidad y:sus obligaciones, to más habitual es que se trate de establecer, como en esta cita de Carballo, algún vínculo entre ambas. Se suele reconocer que toda ficción poética encubre alguna verdad, de índole maral o práctica y que en cierta medida sirve para conocer y explicar el mundo real. Sólo así se explica que de forma recurrente se caracterice al poeta como una especie de sabio, y se subraye la necesidad de que el poeta posea un cierto grado de dominio de la totalidad de las ciencias, por ajenas que parezcan a la poesía. Puede encontrarse esta caracterización en los escritos de Suárez de Figueroa o en los textos panegíricos y apologéticos de Bernardo de Balbuena, Soto de Rojas, Vera y Mendoza, Gutierre Marqués de Careaga o en el anónimo Discurso en loor de la poesía, donde se lee lo siguiente:

\section{"Y aquel qu'en todas ciencias no florece y en todas artes no es ejercitado, el nombre de poeta no merece." 72}

Podría plantearse el porqué de esa necesidad de conocer el mundo real mejor que nadie si se supone que la obra poética no tiene vínculos directos con la realidad. La respuesta está, una vez más, en los conceptos de imitación y verosimilitud, y nos remite de nuevo a la Poética de Aristóteles y su defensa de que la poesía es superior a la historia porque la segunda da cuenta de lo sucedido y la primera de lo que podría suceder, siendo un requisito previo para ello que se aprehenda el funcionamiento esencial de la naturaleza. Como explica Luis Alfonso de Carballo, "de que es necessario saber el Poeta algo de cada professión, no ay duda"73.

Como es obvio, la poética de época, así como la de cada autor concreto, aparece actualizada en los textos literarios, que revelan los efectos de todas las consideraciones analizadas previamente. Hay autores que ya en el prólogo de sus obras dejan constancia de los principios poéticos que han seguido al crearlas, y dan cuenta de la postura que mantienen en los debates sobre la índole de la verosimilitud, sobre el papel de lo histórico y factual en la poesía o sobre la moralidad o la inmoralidad de la mentira literaria.

${ }^{71}$ L. A. de Carballo, Cisne de Apolo, cit., 103. Cfr. 111-112.

${ }^{72}$ Anónimo, Discurso en loor de la poesía (Sevilla 1608), en La teoría poética en el Renacimiento y Manierismo españoles, cit., 319.

${ }^{73}$ L. A. de Carballo, Cisne de Apolo, cit., 77. Cfr. 132-142. 
Así, por ejemplo, en el prólogo del Amadís de Gaula, entre juegos convencionales, se afirma que los sabios antiguos quisieron componer las hazañas "sobre algún cimiento de verdad", y se defiende que es entonces cuando lo fingido tiene más valor; por el contrario, se nos dice, "otros uvo de más baxa suerte que escrivieron, que no solamente edificaron sus obras sobre algún cimiento de verdad, mas ni sobre el rastro della"74. También Montalvo hace depender el valor de la obra de la medida de su verdad, pero no necesariamente una verdad histórica y factual, sino moral, pues señala como único fruto de las historias fingidas los "buenos exemplos y doctrinas". Una vez más hay que contar con la verosimilitud, ya que se tiene por falta que la obra parezca más patraña que crónica, y para evitarlo se utilizan distintos recursos que acercan la novela a la historia, como, por ejemplo, el tópico del manuscrito hallado.

También se juega con la ambigua relación entre lo real y lo ficticio en la introducción de una obra posterior, La Lozana andaluza, en donde Francisco Delicado afirma que tan sólo dirá lo que vio y escuchó, y que no extrajo nada de otros libros, sino que ha sacado su retrato del natural, como advertirán -nos dice- quienes hayan conocido a la protagonista en Roma, aunque reconoce la diferencia que existe entre la realidad y la literatura al advertir que tal vez ella aparezca más sabia de lo que se mostraba, pero no porque no lo fuese en verdad, sino porque el autor, como artista metódico, la observó hasta conocerla mejor que nadie $^{75}$.

Un autor de la época en cuya obra se evidencian los múltiples conflictos que origina la relación entre la verdad y la mentira, la ficción y la historia o la verosimilitud y lo increíble es Cervantes, cristiano fervoroso que se debate de continuo en el dilema que supone alcanzar el grado de apariencia de verdad que reclama el arte y que permite al mismo tiempo engañar al lector confiado. De ahí, como señala Riley, las vacilaciones que se observan en el Persiles o en el Quijote, donde tan pronto se tilda a Cide Hamete de "fidedigno autor desta nueva y jamás vista historia" como se le desautoriza por su condición de arábigo o se pone en tela de juicio con ironía el hecho de que deje constancia de lo que hacían o hablaban Sancho y Don Quijote cuando estaban a solas ${ }^{76}$. Y sin embargo, Cervantes no deja de mostrar su preocupación por los aspectos técnicos narrativos que se relacionan con la verosimilitud, y protesta, por ejemplo, contra la profusión de detalles intrascendentes, sin pertinencia artística ni relevancia en la trama. En el Quijote se aprecia con claridad la búsqueda del equilibrio entre la ficción, la verosimilitud y una supuesta verdad histórica; se juega, por ejemplo, con los sucesivos hallazgos de los manuscritos que contienen la historia de Don Quijote. Se utilizan índices de factualidad, como las reiteradas protestas del narrador sobre lo cierto de la historia, o la mención de otras fuentes ajenas a Cide Hamete, pero quizás el artificio más logrado sea la aplicación de una óptica realista que deja al descubierto lo ficticio de las imaginaciones del protagonista, de forma que, una vez subrayado el carácter irreal de ciertos acontecimientos, el lector, por contraste, es empujado a creer que los demás son verdaderos.

\footnotetext{
${ }^{74}$ G. Rodríguez de Montalvo, Amadís de Gaula (Barcelona, Planeta, 1991), 3-5.

${ }^{75}$ F. Delicado, La Lozana andaluza (Madrid, Castalia, 1984), 33-36.

${ }^{76}$ E. O. Riley, Teoría de la novela en Cervantes (Madrid, Taurus, 1981), 323-327.
} 
Cervantes es un ejemplo paradigmático de las tensiones que se establecen en torno a la verdad, la mentira y la ficción. Además de la reflexión implícita y a veces explícita al respecto, su obra refleja el juego de convenciones en el que tiene un papel determinante la instancia del lector, referente continuo para el poeta, que se dirige a él y que calcula los efectos que sobre él tendrá la obra.

Cabe concluir este trabajo con las consideraciones que expresa Diego Dávalos y Figueroa en su Primera parte de la Miscelánea Austral y que representan un enfoque distinto de la interacción que se produce entre la realidad factual y la ficción poética. Dávalos se admira de la manera en que la poesía "representa a nuestros sentidos lo que pinta con poética invención", de tal forma "que lo sella y fija en el alma"7. Dicho en otros términos, la obra literaria está hecha de ficciones, pero no es en sí una ficción, sino, como se ha defendido en estas páginas, algo real y sensible que a su vez modifica la realidad de los lectores. De ahí, por ejemplo, que en la época que nos ocupa se prohibiera la exportación de obras de ficción al Nuevo Mundo. La literatura, en fin, crea realidades, aunque sean realidades ficticias, y esas creaciones llegan a condicionar la percepción y la comprensión del mundo factual, histórico y extraliterario, en el que vive su lector.

\section{BIBLIOGRAFÍA}

ALBALADEJO, T., Teoría de los mundos posibles y macroestructura narrativa (Alicante, Universidad de Alicante, 1998).

ANÓNIMO, Discurso en loor de la poesía (Sevilla 1608), en La teoría poética en el Renacimiento y Manierismo españoles (Barcelona, Puvill, 1986). ARISTÓTELES, Poética (Sevilla, Padilla, 1997).

AUSTIN, J. L., Cómo hacer cosas con palabras (Barcelona, Paidós, 1990)

BALBUENA, B. de, Compendio apologético en alabanza de la poesía (México 1604), en Porqueras Mayo, A., La teoría poética en el Renacimiento y Manierismo españoles, cit. BALBUENA, B. de, El Bernardo (Madrid 1624), en La teoría poética en el Manierismo y Barroco españoles, (Barcelona, Puvill, 1989).

BOBES NAVES, C., La novela (Madrid, Síntesis, 1993).

BOOTH, W. C., La retórica de la ficción (Barcelona, Bosch, 1978).

BOURNEUF, R. y OUELLET, R., L'univers du roman (París, P.U.F., 1981).

CARAMUEL DE LEBKOWITZ, J., Primus Calamus (1665), en La teoría poética en el Manierismo y Barroco españoles, cit.

CARBALlO, L. A. de, Cisne de Apolo (Medina del Campo, 1602; Madrid, CSIC, 1958).

CARRILLO Y SOTOMAYOR, L., Libro de la erudición poética (1611; Sevilla, Alfar, 1987).

CASCALES, F., Tablas poéticas (Murcia, 1617; Madrid, Espasa-Calpe, 1975).

COLMENARES, D. de, Respuesta a la carta antecedente por sus mismos puntos (1624), en La teoría poética en el Manierismo y Barroco españoles, cit. 
DÁVAlos Y FIGUEROA, D., Primera parte de la Miscelánea Austral (Lima 1602), en La teoría poética en el Renacimiento y Manierismo españoles, cit.

DELICADO, F., La lozana andaluza (Madrid, Castalia, 1984).

DOLEZEL, L., Heterocósmica. Ficción y mundos posibles (Madrid, Arco/Libros, 1999).

DOLEZEL, L., "Mundos de ficción: densidad, vacíos e inferencias", en Pozuelo, J. M. y Gómez, V. (editores), Mundos de ficción. Actas del VI Congreso Internacional de la Asociación de Semiótica (Murcia, Universidad de Murcia, 1996).

ENCINA, J. del, Cancionero (Salamanca 1496), en La teoría poética en el Renacimiento y Manierismo españoles, cit.

FARIA E SOUSA, M. de., Los Lusiadas de Luis de Camoens (Madrid 1625), en La teoría poética en el Manierismo y Barroco españoles, cit.

FARIA E SOUSA, M. de., Juicio de rimas varias de Luis de Camoens (Lisboa 1685), en La teoría poética en el Manierismo y Barroco españoles, cit.

FRAU, J., Realidad y ficciones del texto literario (Sevilla, Padilla, 2002).

GARCÍA BERRIO, A., Introducción a la poética clasicista. Cascales (Barcelona, Planeta, 1975).

GARRIDO DOMÍNGUEZ, A., Teorías de la ficción literaria (Madrid, Arco/Libros, 1997). GENETTE, G., Ficción y dicción (Barcelona, Lumen, 1993).

GONZÁLEZ, F., Carta encomial y apologética (Valencia 1616), en La teoría poética en el Renacimiento y Manierismo españoles, cit.

HAMBURGUER, K., La lógica de la literatura (Madrid, Visor, 1995).

HUARTE DE SAN JUAN, J., Examen de ingenios para las ciencias (Madrid, Editora Nacional, 1976).

IGLESIAS SANTOS, M., "El sistema literario: Teoría Empírica y Teoría de los Polisistemas", en Villanueva, D. (compilador), Avances en Teoría de la Literatura (Santiago de Compostela, Universidade de Santiago de Compostela, 1994).

ISER, W., El acto de leer (Madrid, Taurus, 1987).

ISER, W., "La ficcionalización: dimensión antropológica de las ficciones literarias", en A. Garrido Domínguez (compilador), Teorías de la ficción literaria (Madrid, Arco/Libros, 1997).

LERÍN Y GARCÍA, J. de, El bien y el mal de las ciencias (París 1626), en La teoría poética en el Renacimiento y Manierismo españoles, cit.

LÓPEZ DE CUÉLLAR Y VEGA, J., Declamación histórica y jurídica en defensa de la poesía (Madrid 1670), en La teoría poética en el Manierismo y Barroco españoles, cit.

LÓPEZ DE MENDOZA, I., Prohemio e carta (1449), en La teoría poética en el Renacimiento y Manierismo españoles, cit.

LÓPEZ PINCIANO, A., Philosophía antigua poética (Madrid, Biblioteca Castro, 1998).

LUNA, J. de., Segunda parte de la vida de Lazarillo de Tormes (París, 1620; Madrid, Cátedra, 1988).

MACHEREY, P., Para una teoría de la producción literaria (Caracas, Universidad Central de Venezuela, 1974).

MARTÍNEZ BONATI, F., La ficción narrativa (Su lógica y ontología) (Murcia, Universidad de Murcia, 1992).

MONTEMAYOR, J. de, La Diana (Barcelona, Crítica, 1996).

MUÑ́n, S., Tragicomedia de Lisandro y Roselia (1542), en La teoría poética en el Renacimiento y Manierismo españoles, cit. 
PELLICER DE TOVAR, J., Epílogo de los preceptos del poema heroico (Madrid 1625), en La teoría poética en el Manierismo y Barroco españoles, cit.

PLAUTO, Obras morales y de costumbres (Madrid, Gredos, 2001).

POZUELO YVANCOS, J. M., Poética de la ficción (Madrid, Síntesis, 1993).

QUEVEDO, F. de, Premáticas del desengaño contra los poetas güeros, en Prosa festiva completa (Madrid, Cátedra, 1993).

RILEY, E. O., Teoría de la novela en Cervantes (Madrid, Taurus, 1981).

RODRÍGUEZ DE MONTALVO, G., Amadís de Gaula (Barcelona, Planeta, 1991).

SÁNCHEZ DE LIMA, M. de, Arte poética en romance castellano (1580), en La teoría poética en el Renacimiento y Manierismo españoles, cit.

SOTO, H., Emblemas moralizadas (Madrid 1599) en La teoría poética en el Renacimiento y Manierismo españoles, cit.

SUÁREZ DE FIGUEROA, C., Plaza universal de todas las ciencias y artes (Madrid 1615) en La teoría poética en el Renacimiento y Manierismo españoles, cit.

SUÁREZ DE FIGUEROA, C., Varias noticias importantes a la humana comunicación (1621), en La teoría poética en el Manierismo y Barroco españoles, cit.

TORRE, E., Ideas lingüísticas y literarias del Doctor Huarte de San Juan (Universidad de Sevilla, 1977).

TORRE, E., Sobre lengua y literatura en el pensamiento científico español de la segunda mitad del siglo XVI (Universidad de Sevilla, 1984).

VALDÉS, J. de, Diálogo de la lengua (Madrid, Cátedra, 1984).

VENEGAS, A., El momo de León Baptista Alberti (Alcalá 1553), en La teoría poética en el Renacimiento y Manierismo españoles, cit.

VILLANUEVA, D., Teorías del realismo literario (Madrid, Espasa-Calpe, 1992).

ZABALETA, J. de, Errores celebrados (Madrid 1653), en La teoría poética en el Manierismo y Barroco españoles, cit. 
